\title{
Framework for Development of a Web based System for Students' Appraisal on Teaching Performance of Lecturers in Federal College of Wildlife Management, New Bussa, Niger State, Nigeria
}

\author{
J. O. Adigun \\ Federal College of Wildlife \\ Management, New Bussa, \\ Niger State, Nigeria
}

\author{
E. A. Irunokhai \\ Federal College of Wildlife \\ Management, New Bussa, \\ Niger State, Nigeria
}

\author{
Onihunwa J. O. \\ Federal College of Wildlife \\ Management, New Bussa, \\ Niger State, Nigeria
}

\author{
Jeje C. A. \\ Federal College of Wildlife Management, New \\ Bussa, \\ Niger State, Nigeria
}

\author{
Dada O. S. \\ Federal University of Kashere, \\ Gombe State, Nigeria
}

\begin{abstract}
In this paper, framework for provision of a web based system for students' appraisal on teaching performance of lecturers (SATP) was developed. Many existing lecturer appraisal systems are superior based and are mostly focused on administrative performances of the lecturers, thus, they prevent students that are direct recipients of lecturers' output to voice their opinion about the teaching competencies of their lecturers. The SATP allows the students to evaluate the teaching competency and performance of lecturers and provides report about lecturers' teaching competencies to the school management for decision making. This is with the view to improving educational quality in higher institutions in Nigeria. Domain Driven Design was employed in designing the SATP client-server architecture and its framework. Development of this framework involved the establishment of stakeholders required by the system: these included the higher institutions, lecturers and students. The detailed attributes and functions of these stakeholders as well as relationship and interaction between the stakeholders were used to gather the requirements of the SATP specified using use case diagram. Furthermore, the site map of the SATP which explains the implementation of the framework to be designed was detailed. The SATP design allowed for low start-up cost as it only requires a central server and low requirement client system including mobile phones already possessed by many students. It is believed that the system is cost effective complements to traditional lecturer appraisal system that will allow students to voice their opinion about their lecturers' teaching competencies.
\end{abstract}

\section{General Terms}

Human Computer Interaction

\section{Keywords}

Lecturer Appraisal system, Teaching Competencies evaluation system, Teaching Performance Evaluation system

\section{INTRODUCTION}

Nowadays, computers have been adopted to support many aspects of education including computer aided instruction, instruction recordings, provisioning of assistive technology for the disabled, delivery of learning, training, or educational program by electronic means computer network and internet in some way to provide or support training, educational or instructional material using myriads of computing devices [1].

It is the contention of this study that ICTs can also be annexed to provide feedbacks to government, educational actors and policy makers, parents of students and school authority on results of lecturers' appraisal from students' judgement. This is important because lecturers differ in their abilities and aptitudes. There is always difference in the quality and quantity of the same lecture delivered by two different lecturers. Therefore, performance appraisal is necessary to understand each employee's abilities, competencies, relative merit and relative worth to an educational institution. Performance appraisal rates the employees in terms of their performance.

One of the basic needs of an educational institution is to appraise her lecturer's performance continuously to find out whether they improve or not and know the perspective of the students about their style of delivering lecture. In similar vein, lecturers want to know how well they perform on the job. The need for performance appraisal of lecturers in Nigerian educational institutions is not far-fetched; it is because the problem of students' under-performance at all levels in Nigeria has been a much discussed educational issue.

In solving any problem however, it is pertinent to understand the causes of such problems. Many causes or agents have been studied as the etiological starting point for investigating the phenomena of school failure or success. Authors in [2] gathered that these causes are looked into from several perspectives including the role of the students, teachers, parents or family, school environment, society, government, some works that concern lecturers among these are effects of: attitudes of lecturers to continuous assessment [3] [4] [5] [6], teachers' teaching methods [7] [8] and teachers' competencies [9] [10].

From the foregoing, many of these causes can be linked to the non-effectiveness of lecturers, therefore at the heart of solving the problem of students' underperformance is the need to 
allow the students to periodically carry out continuous lecturers' appraisal as the students are the direct recipients of the lecturers' discharge of duties and thus can provide insight to what particular lecturer(s) is/are doing that is affecting their rates of learning and provide feedback to ways by which lecturer(s) can improve their method of instruction.

\subsection{Statement of the problem}

There is decline in the after school performance of students in Nigerian tertiary institutions such that the quality of graduates being produced by the nation's tertiary institutions is questionable [6]. Little wonder why graduates are subject to re-examination by companies and establishments that want to employ graduates through conduct of aptitude tests. Also, graduates of a higher institutions pursuing higher learning in other schools in Nigeria and abroad are oftentimes subjected to re-examination through different means. Therefore, there is need to promote learning and improve students' academic performance in tertiary institutions.

It is the contention of this study that at the heart of improving students' learning is the improvement of teachers' effectiveness through students' appraisal technique because many students know what their lecturers are doing that are discouraging their attitude to learning and inhibiting their optimal performance, however, due to inadequate lecturer appraisal by the students a lot of students finds it extremely difficult to voice out their opinion about lecturer's general performance hence, they result to side talk about their lecturer's pattern of delivering lectures and general attitude to work. They would prefer keeping all excesses about their lecturers to themselves and colleagues rather than getting across to the school authority for fear of intimidation and victimization.

Specifically, the following problems are identified to be solved at the end research in the current system of appraising lecturer performances in many Nigerian tertiary institutions:

- Students (the direct recipients of lecturer's productivity) are not allowed to evaluate the lecturer

- Staff appraisal is only done seasonally (annually or triennially) which make the system too rigid

- Due to the rigidity of the current system, it is not easy to retrieve appraisal data about staff performance as at when needed.

In the light of the above, there is need for a web based lecturers evaluating system to be carried out by students anonymously from which school administrators can get feedback about lecturers' classroom performance by the students. However, it should be noted that the system will only be a complement to the existing system as the students will only be able to evaluate classroom performance of the lecturers and not managerial or other extracurricular performances.

\subsection{Aim and Objectives}

The research aimed at developing framework for development of a web based system for students' appraisal on teaching performance (SATP) of lecturers in higher institutions in Nigeria. The specific objectives include:

i. To analyse the requirement and specification of SATP system that allow students (the direct recipients of lecturer's productivity) to evaluate their lecturers ii. To design the framework of SATP system to allow for flexible retrieval of appraisal data anytime it is needed

iii. To design the framework of a SATP system that reduces lecturers' coercion of students into giving falsified evaluation reports or intentional falsification of judgements about a lecturer by sets of students.

\subsection{Significance of the Study}

The study is of importance to the following:

i) It enables students to voice their opinion about areas of weakness of their lecturers and what their lecturer(s) is/are doing that are reducing their morale to optimal learning and inhibiting their optimal performance thus, the outcome of the study is promising to improving students' academic performances.

ii) It helps the lecturers to know their area of weakness and help them to work on improving their performance in such area.

iii) It helps the management in ensuring that the lecturers discharge their duties adequately and could serve to support decision on lecturer promotion and other reward system.

\section{LITERATURE REVIEW}

Students' appraisal or evaluation on performance in classroom teaching is not recently introduced into the world of education. As a matter of fact, the initiative taken to evaluate teaching has started as early as the 1915 [11]. According to authors in [11], the first teacher rating scale was published in 1915 and the first study of students' evaluation of teacher effectiveness was written in the 1920s. For many decades, the outcome of students' evaluation of teaching performance is seen as an important tool to measure the effectiveness of teaching quality. It has been used to reflect on qualities associated with good teaching such as lecturers' knowledge, clarity, classroom management and course organization.

Despite the fact that students' evaluation of lecturers' performance is not a recent phenomenon, extensive research by psychologists and educators have consistently reported that students' evaluation on performance were questionable in terms of its validity and reliability. The outcome of the evaluation was reported biased as the student assessed the teaching performance based on non-related learning measures which included race, gender, political ideology, socioeconomic status, attractiveness [12] [13] [14] [15] [16]. In other instances, students' evaluations were reported influenced by the lecturers' smiles, gestures and other mannerisms, rather than the lecturers' knowledge, clarity, organization or other qualities associated with good teaching [14]. These critics felt that this type of evaluations were not useful as the ratings that students awarded did not bear any relationship with objective measures of learning or what educators accomplished in the classroom. To overcome this problem, this study validates the responses of the students by adopting pre-test, post-test design which will be statistical analysed to test the consistency of the students' responses.

According to [17], teachers were rated based on two possible ratings, satisfactory or unsatisfactory, in previous teacher evaluation systems. This system made it impossible to distinguish great teaching from good, fair or poor teaching. Consequently, it was also difficult to conclude if teaching 
expectations were met or to identify specific lecturers that need additional support tailored to their specific needs. To overcome this problem, the instrument used in this study to evaluate the lecturers' performance were given 5 rating scale namely A: Excellent; B: Good; C: Satisfactory; D: Fair; F: Poor. The scale enabled the students to perform ratings from the most ineffectiveness to the highly effectiveness of the lecturers' characteristics been measured. This would give the lecturers and the learning institution a clearer picture of the performance assessed by the students. The lecturer concern would be able to know whether expectations were met and the managing directors can be provided with clear information to support their decisions.

More specifically, authors in [18] worked on the Design and Implementation of Lecturer Evaluation System Using ELECTRE Method in Web-based Application. They created a Lecturer Evaluation System by Students using Elimination et Choix Traduisant la Realite (ELECTRE) method to assist and facilitate in making decision related to lecturer's evaluation to get the best lecturer's recommendation. However, their design raised some challenges:

i) There are students who do not fill out the questionnaire form completely hence the evaluation process becomes ineffective and there is a possibility that data obtained is not valid.

ii) Evaluation activities of lecturers take a lot of time, because the procedure used has long stages. In addition, there are often lecturers in the classroom without any students or the number of students who attend just a little.

Careful study of the method adopted also shows that the method expected all students to evaluate each lecturer before decision is made using the ELECTRE method about the particular lecturer, thus the rationale behind the challenges they faced. Furthermore, their design tends to focus on getting best lecturer rankings and does not give in-depth details about lecturers' general attitude to students in classroom. To overcome this, this study allows analysis of the data (students' responses) to be possible as at when needed once one or more students have evaluated a particular lecturer. Furthermore, results of analysis on individual lecturer generated as a report contains in-depth details about lecturers' general attitude to students in classroom.

\section{METHODOLOGY}

In order to allow for proper analysis of the current scenario and also provide a platform to test run the system, the study adopts a domain driven design and Federal College of Wildlife Management, New Bussa (FCWM) was used as the domain or case study of this research.

\subsection{Analysis of the existing system in the domain of research}

Been the domain of this research, the most important stakeholders in this project is the project customer, that is, Federal College of Wildlife Management, New Bussa (FCWM). FCWM currently operates two methods of lecturer appraisal system that are majorly superior based lecturer appraisal system; this implies that students are not involved in the lecturer appraisal process. There are two basic methods used in evaluating lecturers in the university, both methods are superior based.

The first method has to do with selection of an academic quality control and disciplinary committee that is saddled with responsibility of going from classes to classes during the lecture hour and during examination, the committee ensure decency in the classroom teaching and examination procedure by making sure that everything is been done following de facto standard. This committee is saddled with the responsibility of evaluating and reporting about lecturers that are not carrying out their duties as expected of them to enhance students' academic performance. The outcome of the process that is gathered by this committee will then be used to provide judgment about lecturers. Erring lecturers in the discharge of their duties are disciplined based on the committee's judgment.

In the second method, the head of department or head of section (HOD) is the one saddled with the responsibility of scoring the lecturers' performance. A manual appraisal form (usually called annual performance evaluation report (simply APER form) is distributed to staffs going on promotion prior to the time the promotion exercise is to be conducted. The concerned staffs fill in the personal records, undergone training, job description and assigned task section. Afterward, the superior in the office (usually the head of department) is required to complete the section that has to deal with performance of the lecturer on routine job schedule (lecturing ability and how it translates to students' learning outcome), adequacy of relationship with students and other duties assigned in terms of organization, achievement of objectives, general ability, people skill as pertaining to relationship with fellow staffs. The superior is also expected to identify areas of training needs of the concerned lecturer and whether he or she would like to continue working with the lecturer or suggests reposting of the lecturer to another unit or department. Also, reports of the academic quality control and disciplinary committee on a particular lecturer is retrieved by the HOD when evaluating the lecturer.

All these data are collected using questionnaire-like form which uses open ended questions, rating and grading scales and dichotomous formats. On submission of the APER form, the responses are scored and used to grade the lecturer. This forms part of the assessment of lecturer during promotion exercise and selection to key position.

\subsection{Limitations of the current system in the domain of research}

The current lecturer appraisal system being operated in the school is limited in operations due to the fact that evaluation work is solely the work of the management through academic quality control and disciplinary committee and the head of department. However, since the academic quality control and disciplinary committee and the Head of Department (HOD) are not the direct recipients of the lecturers' services, it may be difficult to evaluate outcome of learning rightly. Therefore, the following limitations were discovered from the current appraisal system procedure:

$>$ The direct recipients (students) of lecturers' services are denied the ability to assess their service giver (lecturers).

$>$ Careful analysis also shows that in the current system, appraisal data are not easily retrievable

$>$ The current system is more focussed on administrative requirements from the lecturers and less on classroom performance

$>$ The current system is also prone to either prejudice or partiality on the part of the HOD to the concerned 
staff based on rapport between the staff and the HOD

This necessitates the need to complement the current evaluation system with one that will be from the students' perspective, thus, the need to develop a Students' Appraisal on Teaching Performance (SATP) of Lecturers.

\subsection{Requirements and Specifications \\ Analysis}

The SATP is a five point likert scale questionnaire-like form to be presented to students to evaluate various academic abilities (personal and academic/teaching characteristics) of their lecturers. Some challenges are foreseen to come up from evaluating the lecturers from the students' perspective, these include:

i) Coercion of students by lecturers into giving falsified evaluation

ii) Intentionally falsifying judgements about a lecturer by sets of students due to reasons best known to them

In order to avoid the foreseen challenges and at the same time deal with challenges of the current system, the SATP is required to be a web based lecturer appraisal system from the students' perspective that is being statistically analysed. Herein, the appraisal admin is dedicated to running statistical analysis on appraisal responses of the users (students) about a particular lecturer.

The use case of the SATP is presented in Fig. 1. It shows that the system includes modules that allow the students to view the list of lecturers and their basic information. Afterward, the student selects whether to conduct first or second evaluation on a lecturer he or she wants to appraise next, fill the appraisal form (which include 5-point likert scale questionnaire) and submit the filled form to the server for processing. The admin is responsible for adding and updating staff information, adding and updating evaluation questionnaire questions, and running statistical analysis on the responses of the respondents to generate lecturers' appraisal record anytime it is needed. $\mathrm{He}$ is also responsible for printing the appraisal data for use.

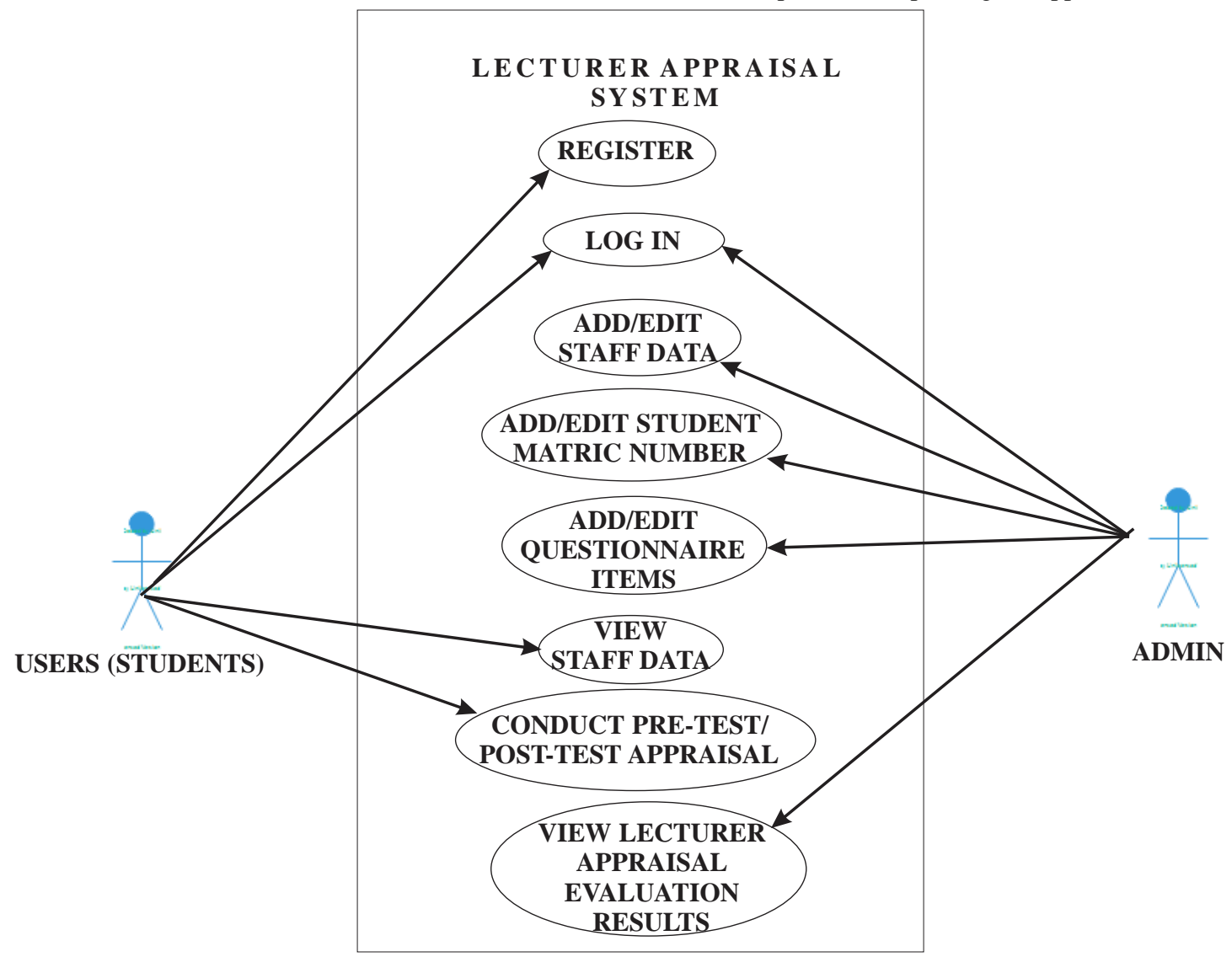

Fig 1: Use case diagram of the SATP system

The functional and non-functional requirements of the system as gathered from the analysis in the previous section are depicted below:

\section{Functional Requirements}

- Admin has to input matriculation numbers of all eligible students to prevent unauthorised access

- Registration of the students is done by each students.

- Both students and admin are given unique username (matric number/admin user name respectively) and password.

- There is one already registered admin, however, other admins can be registered.

- After logging in, students can perform first and second evaluation of lecturers using a five point likert scale like questionnaire form which is presented to the students

- After logging in, Admin can add/edit lecturer data so that students can identify lecturers to evaluate.

- Admin can add/edit contents of evaluation 
questionnaire to be presented to students

- Admin can run statistical analysis on responses of students about individual lecturers anytime there is need for it and print result of evaluation of individual lecturer.

\section{Non-functional requirements:}

- $\quad$ Both web and database server that possess $24 \times 7$ availability

- Accessibility to widely used operating system and browsers in the region of deployment

- System is Cross platform as it is web based and made available through browser which is compatible with virtually all modern browser including mobile system browsers

- Better component design to get better performance at peak time

- Flexible service based architecture is highly desirable for future extension

- Efficient $3 \mathrm{G} / 4 \mathrm{G}$ internet connectivity

\subsection{System Design}

This section describes the approach to the creation of a new system. This important phase provides the understanding and the procedural details necessary for implementing the system recommended in the system analysis in the previous section. The SATP being a decision support system (DSS) consists of the following components:

The front end serves as the web interface or dialog manager that is to be presented to the user through a web browser in which the user (students and administrators) are able to log in to carry out needful actions on the DSS namely appraising the lecturers of the department. The front end is developed using HTML, CSS and JQuery.

The DSS database is the back end that consists of the qualitative and quantitative data (responses of the students). The DSS database system was developed using MySQL database management system.

The base model which is to be hosted on Apache server was developed using Personal Homepage Preprocessor (PHP). The base model is used to modify and retrieve contents of database and enable managers and decision makers to perform quantitative analysis on the DSS database, it therefore gives the system administrator ability to generate appraisal results for lecturers individually and collectively. The base model is programmed to make statistical analysis such as frequency counts, percentages and means score based on Eq. (1), mean score deviation based on Eq. (2) and evaluation percentage of a lecturer based on Eq. (3). The statistical results of the appraisal data currently in the system can be generated by the admin at any time it is required.

? $=\frac{\sum_{1}^{n_{q}} X_{i}}{n_{q}}$

M.D $=\frac{\sum_{1}^{n_{q}} X_{i-} d}{2 * n_{q}}$

$?_{0}=\frac{\sum_{1}^{n_{S}} \text { 国 }}{F} * 100 \%$

Where

$$
i=\text { case " } i \text { " which represents a particular character }
$$

\author{
traits/attribute expected of a lecturer \\ $X_{i}=$ rating value of the variable for attribute " $i$ " of a \\ lecturer as rated by a student \\ $n_{q}=$ Numbers of variables $(i)$ been measured on a \\ lecturer that is, number of questionnaire items \\ ? $=$ mean rating of a lecturer as gotten from responses of \\ a particular student that have evaluated quality of \\ attribute of a lecturer
$d=$ average rating value expected of lecturer at satisfactory level \\ $n_{s}=$ Number of students that rated a lecturer \\ $F=$ Total rating value expected of a lecturer given \\ multiple of $d * n_{s}$
$\theta_{0}=$ Evaluation percentage of a lecturer as derived from responses of entire students that evaluated the said lecturer

To validate originality of the responses of the students, the students are to be presented with first and second evaluation (pre-test and post-test), any evaluation on a lecturer by a student that is not conducted first and second time is disqualified. Afterward, difference of mean statistics is to be conducted on the pre-test and post-test response the studentlecturer pair to determine consistency of the students' response. A mean error $\left(\right.$ ta $\left._{d}\right)$ value is generated and any mean error value above $10 \%$ is rejected as invalid. This is expected to prevent random evaluation response from students. The mean error is calculated using Eq. (4).

The validity and reliability of students' response is therefore ensured by warning the students of consequences of rejection of their responses on any lecturer while at the same time a minimum number of completed evaluations is required of every student.

$$
?_{d}=\left|\frac{\sum_{1}^{n} q}{4 * n_{q}} * 100 \%\right|-------------(4)
$$

Where

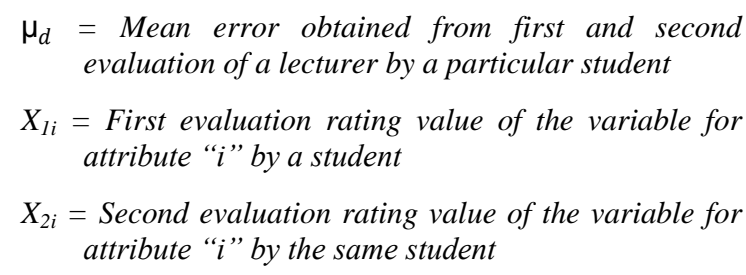

\subsection{Site map of the system}

The first important thing to do in this step is to get all ideas for content down in a site map as described in Fig. 2.The site map presented in Fig. 2 shows that the homepage links to the Admin and Student authentication pages. After the Admin has been authenticated, the admin is allowed to view four (4) different pages which include entering or modifying of evaluation questionnaire, editing of evaluation student's matriculation number, running of statistical analysis on the responses about lecturer and entering and editing of lecturer biodata. The admin prints the result of evaluation of a lecturer from the running of analysis module. The students can either authenticate or register. If the student chooses to register, after registration, the student is redirected to the authentication page. The students' authentication page leads to the students' menu page which leads the student to perform first and second evaluation. 


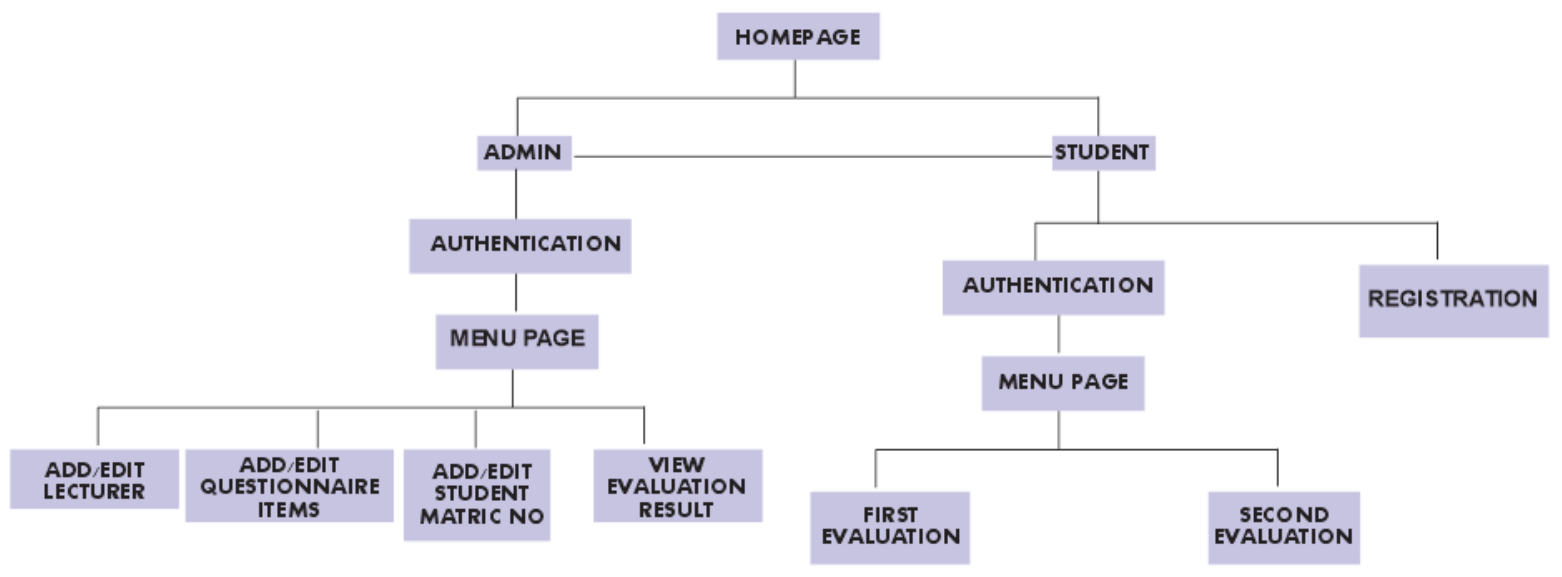

Fig. 2: Site map of the SATP system

\section{SYSTEM IMPLEMENTATION}

It is noteworthy to state that the prototype of the system has not yet been completed as at the time of compilation of this report, hence the screen shot of the prototype of the system is not presented in this paper, however, the system's implementation is well spelt out in this section. The Students' Appraisal on Teaching Performance of lecturers (SATP) web application based on the requirements and specification analysed and designed in previous section is a client-server application.

The SATP User Interface was developed using Adobe Dreamweaver an Integrated Development Environment (IDE), the IDE was equally adopted to write the codes. MYSQL Server, a Relational Database Management System, was used to develop the database system. Personal Home Page PreProcessor (PHP) is used to communicate with and manipulate the database. The primary features of the PHP are that it is object-oriented and a cross platform language meaning that the programs can run across several platforms such as Microsoft Windows, Apple Macintosh, Linux, and so on. PHP ports better with MySQL database, therefore, MySQL database was used as the database management system.

In a clearly spelt format, the web application is being developed in Dreamweaver using the following software:

- User interface: HTML spiced with CSS and JQuery.

- Web or HTTP server: Apache HTTP Server.

- Application server: Personal Home Page PreProcessor PHP.

- The Database application:

- A database management system: MySQL server

- The database system codenamed: dbSATP.

CSS is being used to structure the application to support as many common web browsers as possible by use of varying devices including mobile phones and/or stationary computer system thus, the SATP web application is being designed to be mobile compliant. The size of each page of the application is being scaled down as much as possible to be loaded on 2G/3G and GSM/GPRS transmission network protocols.

\subsection{Implication of framework to sustainable educational development in educational institutions}

The developed framework affords the direct recipients of lecturers' services (that is, students) the ability to access their service giver (lecturers), thus reducing the problem of prejudice and partiality that may ensue from superior based lecturer appraisal system.

The framework also affords management of tertiary institutions to have better access and management of lecturer appraisal data because the SATP hosted on the central server tracks and store every data within the system. Thus further statistical analysis and data manipulation can be performed on the data and information generated can support important decision and selection of academic staffs into key positions in educational institutions.

Furthermore, the framework lecturer appraisal ability of not focussing only on administrative requirements from the lecturers by balancing administrative requirement with classroom performance and personal characteristics of the lecturers from the lecturers' service recipients, that is the students.

\section{CONCLUSION AND RECOMMENDATION}

\subsection{Conclusion}

In this paper a framework on Students' Appraisal of Teaching Performance from students' perspective (codenamed SATP) which is an effective complement to traditional superior based Lecturer Performance Appraisal System was designed. The SATP framework was designed to follow the specification by [17] that suggested that lecturer appraisal should not be based on two possible ratings but on a rating scale.

The SATP framework specifies a pre-test and post-test evaluation of each lecturer by each student which will be statistically validated for acceptance or rejection thus taking care of the setback of the framework offered by [18] which poses the challenge of invalid appraisal data and that of expecting the entire students evaluate each lecturer before decision is made.

The SATP framework is an attractive system that has the potentials of reducing lecturers' coercing of students into giving falsified evaluation reports and at the same time reduce 
intentionally falsifying judgements about a lecturer by sets of students due to reasons best known to them. It is believed that the system is cost effective complements to traditional lecturer appraisal by superior that are not direct recipients of the lecturers' services.

Conclusively, the framework has the capability of improving quality of instruction given to students by lecturers.

\subsection{Recommendation and Future Work}

Due to the ability of the current system to validate lecturer evaluation by student, to generate appraisal data anytime it is needed and allowance of direct recipients of lecturers' services to appraise the lecturer, there is the need to massively embrace the system in educational institutions.

This study do not make use of more qualitative statistical tool for validation of students' choice response on a lecturer such as t-test or ANOVA, thus subsequent research may employ these statistical tools.

Furthermore, it is noteworthy to state that once the prototype is completed, the authors plan to pilot test the software in Federal College of Wildlife Management New Bussa and evaluate the performance of the developed system based on suitability, effectiveness and acceptability through user (students, lecturers and college management) experience.

\section{ACKNOWLEDGMENTS}

Our thanks to the management of Federal College of Wildlife Management that is currently allowing us to test run the software with the students and academic staffs of the college.

\section{REFERENCES}

[1] UIITE (2006). Information and Communication Technology in Special Education. Analytical Survey.

[2] Adigun J. O., Onihunwa J. Irunokhai E. Sada Y. and Adesina O. O. (2015). "Effect of Gender on Students' Academic Performance in Computer Studies in Secondary Schools in New Bussa, Borgu Local Government of Niger State". Journal of Education and Practice. Vol.6, No.33, 2015

[3] Kolawole, E. B. \& Ala, E. A. O. (2014). Effect of continuous assessment and gender on students' academic performance in mathematics in some selected states in the south west Nigeria. Education Research Journal Vol. 4(1): 1-6, January 2014 Available online at http://www.resjournals.com/ERJ @2014 International Research Journals.

[4] Okwu Emmanuel I. and Orum Clement C. (2012). Effect of Continuous assessment Scores on the Final Examination Scores obtained by Students at the Junior Secondary School (JSS) Level in Mathematics. Educational Research (ISSN: 2141-5161) Vol. 3(9) pp. 706-709, September 2012 Available online@ http://www.interesjournals.org/ER

[5] Mwebeza M. (2010). Continuous Assessment and Students" Performance in "A" Level Secondary Schools in Masaka District. Unpublished Masters Dissertation.
Makerere University Kampala. 2010.

[6] Onihunwa J. O., Adigun J. O., Irunokhai E. A., Sada Y. A., Jeje C. A., Adeyemi G. O. and Adesina O. O. (2018). Roles of Continuous Assessment Scores in Determining the Academic Performance of Computer Science Students in Federal College Of Wildlife Management. American Journal of Engineering Research (AJER). 7(5). Pp. 7-20

[7] Adunola, O. (2011),“The Impact of Teachers' Teaching Methods on the Academic Performance of Primary School Pupils in Ijebu-Ode Local cut Area of Ogun State" Ego Booster Books, Ogun State, Nigeria.

[8] Damodharan V. S. \& Rengarajan V. (2010). "Innovative Methods of Teaching" National Research Council, Educational Journal Publication

[9] Akiri Agharuwhe A. and Ugborugbo Nkechi M. (2009). Teachers' Effectiveness and Students' Academic Performance in Public Secondary Schools in Delta State, Nigeria. Stud Home Comm Sci, 3(2): 107-113 (2009).

[10] Efiong C. E. (2015). Teacher quality and student achievement: A review of state policy evidence. Educational Policy Analysis Archives, 8 (1).

[11] Wachtel, H. K. (1998). Student evaluation of college teaching effectiveness: A brief review. Assessment and Evaluation in Higher Education, 23(2), 191-210.

[12] Franklin, J. (2001). Interpreting the numbers: Using a narrative to help others read student evaluations of your teaching accurately. In K.G. Lewis (Ed.), Techniques and strategies for interpreting student evaluations. New Directions for Teaching and Learning, 87, 85-100.

[13] Huston, T.A. (2006). Race and gender bias in higher education: Could faculty course evaluations impede further progress toward parity? Seattle Journal for Social Justice, 4(2): 591-611.

[14] Merritt, D.J. (2008). Bias, the brain, and student evaluations of teaching, St. John's Law Review, 82, 235287.

[15] Riniolo, T.C., Johnson, K.C., Sherman, T.R. \& Misso, J.A. (2006). Hot or not: Do professors perceived as physically attractive receive higher student evaluations? The Journal of General Psychology, 133(1), 19-35.

[16] Vaughns, K.L. (2003). Women of color in law teaching: Shared identities, different experiences. Journal of Legal Education, 53, 496- 504

[17] The New Teacher Project (2010). Teacher Evaluation 2.0. Retrieved from: www.tntp.org・info@tntp.org.

[18] Fajar Masya, Hendra Prastiawan and Destriyani Putri (2017). Design and Implementation of Lecturer Evaluation System Using ELECTRE Method in Webbased Application. International Research Journal of Computer Science (IRJCS). 5(4). 